\title{
A MÚSICA E AS ARTES NA FORMAÇÃO DO PEDAGOGO: POLIVALÊNCIA OU INTERDISCIPLINARIDADE?
}

\author{
Sergio Luiz Ferreira de Figueiredo (UDESC)*
}

\begin{abstract}
RESUMO
O objetivo deste texto é discutir questões relacionadas à música e às artes na formação do pedagogo que atua na Educação Infantil e nos anos iniciais do Ensino Fundamental. O foco da discussão está nos conceitos de polivalência e interdisciplinaridade, buscando entender de que forma tais conceitos se aplicam, se complementam, ou se sobrepõem em documentos oficiais. A metodologia baseia-se nos princípios da pesquisa documental, valendo-se de textos referentes à legislação educacional em diálogo com a literatura. Os resultados apontam para a imprecisão nas orientações legais referentes ao professor que deveria ensinar música ou artes, além da utilização também imprecisa ou incompleta do conceito de interdisciplinaridade em vários textos, o que contribui para a manutenção de práticas educacionais predominantemente disciplinares. No caso do ensino da música e das artes, apesar dos documentos oficiais não indicarem a polivalência como modelo pedagógico, a literatura evidencia a presença desta prática em diversos contextos educacionais. Como conclusão, é evidente a necessidade de mais estudos específicos sobre interdisciplinaridade e ensino das artes a fim de se construir um referencial mais sólido para as propostas educacionais na formação do pedagogo. Palavras-chave: Educação musical. Música e pedagogia. Formação de pedagogos. Polivalência. Interdisciplinaridade.
\end{abstract}

\section{ABSTRACT \\ MUSIC AND THE ARTS IN THE GENERALIST TEACHER EDUCATION: POLIVALÊNCIA OR INTERDISCIPLINARITY?}

The objective of this text is to discuss issues related to music and the arts in the education of the generalist teacher who work in Early Childhood Education and in the initial years of Elementary Education. The focus of the discussion is on the concepts of polivalencia and interdisciplinarity, seeking to understand how these concepts apply, complement each other, or overlap in official documents. The methodology is based on the principles of documentary research, using texts referring to educational legislation in dialogue with literature. The results point to the imprecision in the legal orientations referring to the teacher who should teach music or arts, as well as the imprecise or incomplete use of the concept of interdisciplinarity in several texts, which contributes to the maintenance of predominantly disciplinary educational practices. In the case of the teaching of music and the arts, although official documents do not indicate polivalência as a pedagogical model, the literature evidences the presence of

* Doutor em Música - Educação Musical pelo Royal Melbourne Institute of Techonology - RMIT University. Professor Associado da Universidade do Estado de Santa Catarina (UDESC). Membro do Grupo de Pesquisa Música e Educação (MusE/ UDESC). E-mail: sergiofigueiredo.udesc@gmail.com 
this practice in several educational contexts. In conclusion, the need for more specific studies on interdisciplinarity and teaching of the arts is evident in order to build a more solid frame of reference for the educational proposals in the education of generalists. Keywords: Music education. Music and pedagogy. Generalist teacher preparation. Polivalência. Interdisciplinarity.

\section{RESUMEN}

\section{LA MÚSICA Y LAS ARTES EN LA EDUCACIÓN DEL PEDAGOGO: POLIVALÊNCIA O INTERDISCIPLINARIDAD?}

El objetivo de este trabajo es discutir temas relacionados con la música y las artes en la formación del pedagogo que actúa en jardín de infancia y los primeros años de la escuela primaria. El foco de la discusión es sobre los conceptos de polivalência y interdisciplinariedad, buscando entender cómo se aplican estos conceptos, complementan o solapan en los documentos oficiales. La metodología se basa en los principios de la investigación documental, a partir de textos relativos a la legislación educativa en diálogo con la literatura. Los resultados apuntan a la vaguedad de orientación oficial para el profesor que debe enseñar música o las artes, además también el uso incorrecto o incompleto del concepto de interdisciplinariedad en varios textos, lo que contribuye al mantenimiento de las prácticas educativas predominantemente disciplinarias. Para la enseñanza de la música y las artes, a pesar de los documentos oficiales no indican la polivalência como modelo pedagógico, la literatura muestra la presencia de esta práctica en diferentes contextos educativos. En conclusión, es evidente la necesidad de estudios más específicos sobre la interdisciplinariedad y la educación de las artes con el fin de establecer un marco más sólido para las propuestas educativas en la formación del pedagogo.

Palabras clave: Educación musical. Música y pedagogía. Preparación de maestros. Polivalência. Interdisciplinariedad.

\section{Introdução}

A literatura das áreas de educação musical, das artes e de educação tem apresentado e discutido a formação musical e artística além da prática pedagógica de professores da Educação Infantil e dos anos iniciais do Ensino Fundamental. Tal literatura vem crescendo ao longo das últimas décadas e diversos temas relacionados à música, às artes e à pedagogia apontam para a complexidade deste tipo de formação e de atuação de pedagogos.

A formação inicial do pedagogo ocorre em cursos de pedagogia - licenciatura -, sendo que nos currículos de tais cursos as artes deveriam estar presentes, de acordo com diversas orientações legais. No entanto, tal formação pode ser compreendida e empreendida de várias formas, considerando diferentes entendimentos dos textos legais em distintos sistemas educacionais.
A formação continuada do pedagogo também vem sendo relatada na literatura, tornando-se uma importante ação no sentido de qualificar os profissionais da educação, e as artes fazem parte deste processo formativo contínuo em diversos contextos educativos. Assim como para a formação inicial existem diferentes entendimentos sobre o ensino das artes, a formação continuada pode se apresentar de distintas maneiras, de acordo com as concepções, os interesses e as possibilidades dos sistemas educacionais.

Entre os dilemas da formação artística do pedagogo está a questão da polivalência para as artes - um professor responsável pelo ensino de quatro linguagens artísticas -, já que, em muitos casos, a formação inicial ou continuada refere-se às artes no plural, mantendo, de certa forma, a perspectiva 
polivalente. Diversos professores formadores dos pedagogos, seja na universidade ou em projetos de formação continuada, atuam de forma polivalente, mantendo, de certa forma, a superficialização de conteúdos criticada pela literatura da área, incluída aquela que trata da formação do pedagogo ou do professor especialista em uma linguagem artística.

Em diferentes documentos, o termo "polivalência" deixa de ser mencionado, sendo substituído por "interdisciplinaridade". Este novo termo parece superar os dilemas existentes com relação à formação e atuação do professor de artes na escola, sendo as orientações que se referem à prática interdisciplinar pouco esclarecedoras para o pedagogo ou para o professor formado em uma das linguagens artísticas. Esta mudança na terminologia utilizada em diversas situações sobre o ensino das artes representa, de fato, uma mudança real nos processos de formação de professores nas licenciaturas em artes e na atuação destes professores em sala de aula na Educação Básica? Este é o foco das discussões que se seguem neste texto, levando em conta que tais discussões afetam de algum modo a formação e a prática dos pedagogos na medida em que em seu processo formativo - inicial ou continuado - estes pedagogos terão como referência professores de artes com distintas concepções, incluindo aqueles que acreditam e defendem a polivalência em nome de uma prática interdisciplinar.

\section{Procedimentos metodológicos}

Os procedimentos metodológicos adotados para a realização desta pesquisa seguem os princípios da pesquisa documental. Para Gil (2002), a pesquisa documental é indicada, por exemplo, para o estudo de materiais que poderiam receber tratamento analítico e que ainda não foram estudados sistematicamente. Os documentos podem ser, de acordo com Flick (2009, p. 237), "instrutivos para a compreensão das realidades sociais em contextos institucionais". Neste caso, o presente estudo visa à compreensão de processos de formação de pedagogos para a atuação na Educação Infantil e nos anos iniciais do Ensino Fundamental a partir de orientações legais, com foco específico nos conceitos de polivalência e interdisciplinaridade.
Basicamente foram feitos recortes, para efeito de análise, de dois documentos: a) Diretrizes Curriculares Nacionais para o Curso de Graduação em Pedagogia, licenciatura (BRASIL, 2006) - que tratam da formação inicial do pedagogo em curso superior e incluem o ensino de artes; b) Diretrizes Curriculares Nacionais para a formação inicial em nível superior (cursos de licenciatura, cursos de formação pedagógica para graduados e cursos de segunda licenciatura) e para a formação continuada (BRASIL, 2015) - que tratam de novas orientações gerais que se aplicam a todos os cursos de licenciatura do país. Outros documentos legais foram consultados e incluídos para auxiliar no processo analítico de forma pontual.

A análise dos documentos foi focalizada nos conteúdos referentes às áreas de artes, buscando orientações, objetivos e conteúdos referentes a estas áreas na formação de professores para a Educação Infantil e para o Ensino Fundamental, considerando, também, questões relacionadas à atuação dos pedagogos que lidam com todas as áreas do conhecimento escolar. A literatura das áreas de educação musical e educação que tratam das políticas educacionais, da organização curricular da educação básica e da formação de pedagogos também foi revisada de forma pontual, a fim de contribuir para a discussão proposta. Os dados dos documentos analisados dialogam, sempre que possível, com esta literatura revisada, trazendo elementos que se complementam ao longo do texto.

\section{Caminhos da polivalência}

Os aspectos trazidos para este trecho do texto se referem de forma específica à polivalência relacionada ao ensino das artes, prática iniciada na década de 1970 que definia que um único professor deveria ser responsável pelo ensino de quatro áreas artísticas na escola. De forma direta, a polivalência foi aplicada aos cursos formadores de professores de Educação Artística; de forma indireta, a polivalência para o ensino das artes também atingiu a formação do pedagogo, já que os professores formadores das artes nos cursos de pedagogia são, em grande parte, oriundos de formação específica nas áreas de artes, sendo que a formação de vários destes profissionais está relacionada à Educação 
Artística, que pode ter sido polivalente. Assim, a polivalência pode estar presente direta ou indiretamente no processo de formação de professores em diversos contextos de ensino superior e em diversos sistemas educacionais, sendo esta prática ainda presente nos dias atuais.

Considerando a perspectiva da formação do professor especialista em artes, um dos temas recorrentes na literatura das últimas quatro décadas é a polivalência. Com a Lei ${ }^{0} 5.692 / 71$, foi estabelecida a Educação Artística como parte integrante dos currículos escolares: "Será obrigatória a inclusão de Educação Moral e Cívica, Educação Física, Educação Artística e Programas de Saúde nos currículos plenos dos estabelecimentos de $1^{\circ}$ e $2^{\circ}$ graus [...]" (BRASIL, 1971, grifo nosso) - equivalentes ao ensino fundamental e ao ensino médio atualmente. A formação de professores para a Educação Artística foi normatizada pelo Conselho Federal de Educação (CFE) através do Parecer no 1.284/73 e da Resolução nº 23/73, contendo as Artes Plásticas, as Artes Cênicas, o Desenho e a Música como áreas pertencentes a esta formação (PENNA, 2010). No processo formativo deste professor eram oferecidas disciplinas relacionadas às áreas citadas acima, e tal formação era realizada inicialmente em curso de licenciatura curta, com duração de dois anos, que oferecia uma habilitação geral em Educação Artística, preparando o professor para atuação com as quatro áreas no ensino de $1^{\circ}$ grau (equivalente ao ensino fundamental hoje). Posteriormente, a licenciatura plena, com 4 anos de duração, incluía nos dois últimos anos uma habilitação específica das artes e autorizava o professor a lecionar também no segundo grau (equivalente ao ensino médio hoje). De acordo com Penna (2010, p. 124), a licenciatura plena em Educação Artística "combina essa habilitação geral a habilitações específicas”.

Atrelado à proposta da Educação Artística foi estabelecido o modelo da polivalência, no qual um professor deveria ser responsável pelas quatro linguagens artísticas. Este modelo está definido, conforme Penna (2010), na Resolução CFE $n^{\circ}$ $23 / 73$, que indicava que esta área deveria ser desenvolvida a partir de uma abordagem integrada das diversas linguagens artísticas, o que foi reafirmado pelo Parecer CFE n 740/77: “A Educação Artística não se dirigirá, pois, a um determinado terreno estético" (BRASIL, 1977, p. 26). Ressalta-se a expressão "abordagem integrada" para o ensino das linguagens artísticas, que estabelece uma junção das diferentes formas de arte, sem maiores detalhamentos sobre como tal integração deveria ocorrer, ficando a critério dos profissionais desta área o entendimento e a aplicação das artes de forma "integrada".

De acordo com Penna (2010, p. 125), “[...] a polivalência marca a implantação da Educação Artística, contribuindo para a diluição dos conteúdos específicos de cada linguagem". Os Parâmetros Curriculares Nacionais, ao apresentarem um breve histórico do ensino das artes no Brasil, assumem a diluição e a diminuição dos conteúdos específicos decorrentes da polivalência:

A tendência passou a ser a diminuição qualitativa dos saberes referentes às especificidades de cada uma das formas de arte e, no lugar destas, desenvolveu-se a crença de que bastavam propostas de atividades expressivas espontâneas para que os alunos conhecessem muito bem música, artes plásticas, cênicas, dança etc. (BRASIL, 1997, p. 24).

O resultado desse modelo tem sido criticado pela literatura, evidenciando a fragilidade e superficialização do processo de formação do professor e a atuação deste profissional na escola com relação às artes (FIGUEIREDO, 2004a, 2004b, 2007, 2009; FONTERRADA, 2005; HENTSCHKE; OLIVEIRA, 1999; PENNA, 2002; TOURINHO, 1993). Entre vários fatores presentes no debate sobre a polivalência está a impossibilidade de se preparar um professor em quatro áreas artísticas, em dois ou quatro anos de curso superior, satisfatoriamente, para que este profissional seja competente do ponto de vista artístico e também esteja preparado pedagogicamente para lidar com o ensino de cada uma das áreas artísticas na escola. Soma-se a estas condições de ordem artística e pedagógica a questão do tempo destinado à formação em cada área artística na universidade e a Educação Artística no currículo escolar, que, em geral, era insuficiente para o desenvolvimento de atividades consistentes e significativas em termos de formação na escola. Todos estes fatores contribuíram, em alguma medida, para a desvalorização da área de artes no currículo escolar e para o estabelecimento de ações desiguais em 
todo o país. Em diversos casos, a polivalência não foi adotada como princípio, prevalecendo no ensino de Educação Artística aquilo que o (a) professor(a) desejava incluir no currículo. A presença das artes plásticas nos currículos escolares foi predominante desde a década de 1970, quando da implantação da Educação Artística, sendo até hoje uma área muito presente em diversos contextos educacionais. As justificativas para tal predominância podem estar relacionadas à quantidade de cursos de artes visuais em nível superior oferecidos em várias partes do país e a disponibilidade de professores desta área que assumem o compromisso com a educação básica (PENNA, 2010) de forma expressiva desde a década de 1970, quando se iniciou a Educação Artística e a prática polivalente nas escolas.

Apesar das críticas à polivalência, atualmente ainda se encontra este modelo em diversos sistemas educacionais, mesmo após diversas mudanças na legislação educacional. A própria LDB de 1996 suprime a expressão Educação Artística, substituindo-a pelo ensino de arte, no seu artigo 26. Outros documentos posteriores a 1996 também excluíram a Educação Artística como terminologia e passaram a tratar de ensino de arte. Esta supressão do termo, de alguma forma, suprimiria a prática polivalente, mas não é o que ocorreu em muitos sistemas educacionais brasileiros: "Pode-se afirmar que o ensino de arte nas escolas ainda hoje remete às determinações metodológicas da educação artística, tendo como pressuposto a polivalência e a hegemonia das artes plásticas pela afirmação da arte-educação desde a década de 1970" (SUBTIL, 2012, p. 147). Esta realidade apontada por Subtil em 2012 permanece atualmente em diversos sistemas educacionais, que mantêm um professor de arte que deve ser responsável por todas as áreas artísticas.

A manutenção da polivalência se deve, em grande parte, à determinação de administradores escolares que enfatizam tal prática, o que pode ser verificado a partir do trabalho de Stori (2011), no Paraná, por exemplo, onde em diversos contextos se exige um professor polivalente, ou ainda em editais de concursos públicos para professores da educação básica em diferentes partes do país (DEL-BEN et al., 2016; FIGUEIREDO; MEURER, 2016; PEREIRA et al., 2014). Em diversos casos, os concursos continuam solicitando o professor de artes sem especificações com relação às habilitações dos candidatos, estabelecendo, indiretamente, a prática polivalente, que se confirma em documentos oficiais no que se refere ao ensino de arte em contextos específicos (FIGUEIREDO; MEURER, 2016).

A legislação referente à formação de professores das várias linguagens artísticas também tem sido modificada desde a década de 1970, o que deveria ser mais um elemento em favor da revisão da proposta polivalente nos projetos políticos pedagógicos em todo o país. Diretrizes curriculares para formação de professores em cada linguagem artística foram estabelecidas na primeira década de 2000: para a área de Música, Artes Visuais e Dança, as diretrizes foram aprovadas em 2004 (BRASIL, 2004a, 2004b, 2004c), e para Artes Visuais, em 2009 (BRASIL, 2009), não existindo mais a formação em educação artística, nem a formação do professor polivalente, pelo menos do ponto de vista das orientações dadas pelos documentos oficiais.

Profissionais formados nos cursos de licenciatura em educação artística estão atuando ainda hoje em escolas de educação básica e têm o direito a esta atuação. Muitos destes profissionais polivalentes não aplicam as quatro áreas de artes definidas na legislação, escolhendo o formato e a quantidade de áreas a serem oferecidas aos alunos. O que se poderia considerar é o fato destes profissionais polivalentes possuírem uma habilitação específica, já que desde 1996, para atuar na educação básica, é preciso ter diploma de curso de licenciatura plena. Ou seja, os profissionais habilitados em uma área artística poderiam atuar na área de sua formação, em nome de uma educação mais consistente (FIGUEIREDO; MEURER, 2016), contribuindo para a revisão das práticas polivalentes, que não têm cumprido um papel formativo relevante nas áreas de artes, conforme as críticas apontadas pela literatura já citada.

Outro ponto a ser destacado é que na época da formação em educação artística existia desenho como uma das habilitações, e hoje tal formação não existe mais. $\mathrm{O}$ desenho foi, de alguma forma, substituído pela dança no conjunto das áreas artísticas que pertencem ao ensino de arte (BRASIL, 1997, 2016). A dança, por ser mais recentemente 
incluída como área artística, não passou pela formação polivalente e os profissionais formados em uma licenciatura em dança estão habilitados para uma única área artística. Ou seja, apesar de alguns sistemas educacionais serem favoráveis à polivalência, a realidade pode se apresentar de várias maneiras, em que a polivalência envolveria duas, três ou quatro áreas artísticas, dependendo das escolhas e das competências do professor para atuar com tais áreas. Esta variação de possibilidades para o ensino das artes alterou o princípio do modelo polivalente, no qual o professor deveria atuar com todas as linguagens artísticas definidas para aquele período, mas este assunto também não recebeu maiores atenções dos administradores escolares, gerando diversas formas de se compreender e aplicar o ensino das artes nas escolas. Em síntese, são muitos os tipos de polivalência que poderiam ser aplicados em diferentes sistemas educacionais, mas o que se defende aqui é a atuação do professor de arte na sua área de formação, ampliando a possibilidade de se oferecer experiências significativas e consistentes para os alunos.

O que se verifica na escola brasileira da atualidade é a convivência entre diferentes profissionais das áreas de artes, alguns vinculados à prática polivalente, outros comprometidos com uma única linguagem artística. Administradores escolares também se apresentam de forma favorável ou não à prática polivalente para as artes. Esta situação gera uma grande desigualdade em termos de formação artística que é oferecida na escola. Ressalta-se que a própria legislação vigente prevê liberdade e autonomia aos sistemas educacionais (BRASIL, 1996), o que reforça ainda mais a possibilidade de diversas maneiras de se compreender e aplicar o ensino das artes na escola. Em nome da autonomia, administradores escolares podem considerar a polivalência como a prática mais adequada do ponto de vista operacional, já que envolve um único professor para tratar das várias linguagens artísticas. Contudo, o que se questiona, além da questão financeira atrelada à presença de mais professores de artes nas escolas, é a concepção de ensino de artes que esta condição econômica estabelece, fortalecendo a ideia de que um único professor para as artes é mais adequado.

\section{Polivalência e o curso de Pedagogia}

De um modo geral, a literatura que discute documentos específicos sobre as artes nos currículos escolares em distintos contextos, concursos para professores de artes, dentre outros temas pertinentes às artes, se referem ao professor especialista, seja ele polivalente ou não. Entretanto parte desta literatura tem o foco na formação e na atuação do pedagogo que, em seu processo formativo, deveria receber preparação artística e pedagógica para incluir as artes em sua atuação profissional.

Nos dias de hoje, o curso de Pedagogia deve incluir as artes, de acordo com as diretrizes curriculares específicas deste curso (BRASIL, 2006). Nestas diretrizes estão incluídas as atribuições do pedagogo: "ensinar Língua Portuguesa, Matemática, Ciências, História, Geografia, Artes, Educação Física, de forma interdisciplinar e adequada às diferentes fases do desenvolvimento humano" (BRASIL, 2006, grifo nosso). O artigo $6^{\circ}$ desta mesma resolução trata da estrutura do curso e reitera a presença das artes, no plural, na formação do pedagogo:

Art. 6o A estrutura do curso de Pedagogia, respeitadas a diversidade nacional e a autonomia pedagógica das instituições, constituir-se-á de:

I - um núcleo de estudos básicos que, sem perder de vista a diversidade e a multiculturalidade da sociedade brasileira, por meio do estudo acurado da literatura pertinente e de realidades educacionais, assim como por meio de reflexão e ações críticas, articulará:

[...]

i) decodificação e utilização de códigos de diferentes linguagens utilizadas por crianças, além do trabalho didático com conteúdos, pertinentes aos primeiros anos de escolarização, relativos à Língua Portuguesa, Matemática, Ciências, História e Geografia, Artes, Educação Física; [...] (BRASIL, 2006, grifo nosso).

Historicamente, um dado relevante a ser considerado referente ao curso de Pedagogia é a orientação legal dada pelo Parecer CFE no 252/1969 e pela Resolução CFE no 2/1969 com relação aos principais objetivos de formação nestes cursos com suas várias habilitações. 
A vigência do Parecer CFE $n^{\circ} 252 / 1969$ e da Resolução CFE n ${ }^{\circ}$ 2/1969 perdurou até a aprovação da LDB 9.394/1996, tendo, portanto, vigorado por três décadas. Nesse período, no que diz respeito ao aspecto legal, o curso de Pedagogia voltou-se para dois objetivos principais: formar pessoal docente para o magistério nos cursos normais e formar especialistas para atuação nas escolas de 10 e 20 graus. A preparação do professor primário em nível superior figurava como um 'apêndice' das demais funções do curso, mas viável legalmente e possível de ser implantada no campo prático-institucional (SCHEIBE; DURLI, 2011, p. 94).

Durante essas três décadas mencionadas pelas autoras, a Educação Artística estava sendo implementada e colocada em funcionamento, dirigida de forma específica para a formação de professores especialistas. As discussões referentes à formação em artes não atingiam de forma direta o curso de pedagogia, e se a preparação do professor primário em nível superior é considerada um apêndice do curso, segundo Sheibe e Durli (2011), é possível inferir que as artes não faziam parte de forma consistente na formação do pedagogo para atuação nos anos iniciais da escola naquele período. $\mathrm{O}$ trabalho de Fucks (1991) discute aspectos referentes à ausência gradativa da formação musical nos cursos normais, onde eram formadas as professoras que atuavam nos anos iniciais da escola, sendo um dos poucos trabalhos encontrados na literatura da área de educação musical que tratam da formação musical e artística do pedagogo.

Em diversos trabalhos produzidos a partir dos anos 2000, a questão do ensino das artes nos cursos de pedagogia passou a receber maior atenção. Um levantamento desta produção foi realizado por Werle e Bellochio (2009), trazendo estudos sobre a música na formação e na ação de pedagogos, publicados em Revistas e Anais de Congressos da Associação Brasileira de Educação Musical (ABEM) entre 2001 e 2008. Neste levantamento foram estabelecidas três categorias: formação acadêmico-profissional, formação continuada e educação musical na educação básica. Estas categorias sintetizam os principais focos dos estudos publicados naquele periódico, mas podem ser aplicadas, de um modo geral, a trabalhos produzidos em outros formatos acadêmicos no mesmo período e posteriormente. Manzke (2016) atualizou o levantamento feito por Werle e Bellochio (2009) até o ano de 2013, detalhando dados referentes à formação continuada.

Os trabalhos disponíveis na literatura da área retratam distintos contextos, mas apresentam resultados similares com relação à formação em artes nos cursos de pedagogia. Em diversos casos, tal formação se restringe a uma única disciplina, com carga horária pequena, cujos conteúdos envolvem as várias linguagens artísticas ministradas por um único professor (FIGUEIREDO, 2003, 2004b). Uma única disciplina de artes, um único professor, várias linguagens artísticas, é o mesmo modelo polivalente amplamente criticado na formação e na atuação do professor das diversas áreas artísticas. Desta forma, parece que toda a discussão acumulada com relação à polivalência para o ensino das artes no âmbito da formação do professor especialista não tem alcançado contextos de formação de professores nos cursos de Pedagogia de forma significativa.

O curso de Pedagogia da Universidade Federal de Santa Maria (UFSM), desde 1984, apresenta em seu currículo disciplinas de música, além de outras áreas de artes ministradas por professores especialistas (OESTERREICH; GARBOSA, 2014); a Universidade do Estado de Santa Catarina (UDESC) também incorporou disciplinas específicas de artes em seu curso de Pedagogia, superando a perspectiva polivalente, oferecendo Música e Ensino, Artes Visuais e Ensino, Teatro e Ensino, ministradas por professores especialistas no processo formativo do pedagogo (UNIVERSIDADE DO ESTADO DE SANTACATARINA, 2010). Estas duas instituições são apresentadas a título de exemplos possíveis de inserção da música e de outras artes na formação do pedagogo, com abordagem específica de cada área artística, superando completamente a perspectiva polivalente.

Cabe destacar que o pedagogo atua com todas as áreas do conhecimento escolar e às vezes este profissional é denominado polivalente em sentido amplo. Em seu processo formativo antes da universidade, diversas áreas do conhecimento estiveram presentes por vários anos, estando este professor de certa forma familiarizado com o que se entende por educação geral de crianças. É natural que 
qualquer estudante tenha recebido por vários anos aulas de matemática, português, ciências, história, geografia. Mas no caso das artes, não é incomum que diversas pessoas tenham recebido pouca ou nenhuma formação durante toda a educação básica, sendo menos frequente aquelas que tiveram experiências com diferentes áreas artísticas cujos conteúdos foram ministrados por especialistas nas respectivas áreas. Ao chegar à universidade, o estudante de pedagogia encontrará algum tipo de formação em artes, mas tal formação poderá mostrar-se insuficiente para que o futuro professor sinta-se preparado para atuar com as artes na escola, porque receberá uma formação que mantém, de certa forma, a prática da polivalência para as artes, com pouca carga horária, com um professor responsável por toda a formação, o que conduz à superficialização deste processo formativo e à insegurança do profissional com relação a esta área de ensino (DALLABRIDA; SOUZA; BELLOCHIO, 2014; FIGUEIREDO, 2003).

Em síntese, o pedagogo, formado em curso de licenciatura em Pedagogia, pode ter passado por experiências artísticas em sua formação inicial. Tal formação, em geral, possui pouca carga horária e tem formato polivalente, no qual um professor de arte é responsável pelas várias linguagens artísticas. Em outros casos, o professor de arte na universidade aborda uma única linguagem relacionada à sua formação, o que poderia conduzir a um aprofundamento maior na experiência formadora. De qualquer maneira, o pedagogo deveria inserir, em sua prática pedagógica, as demais artes, necessitando de formação também específica nas outras linguagens artísticas. A formação continuada pode auxiliar neste processo formativo, familiarizando o pedagogo com diversas áreas artísticas que pudessem ser articuladas em seu dia a dia na escola, sendo esta formação discutida na literatura da área de educação musical com resultados positivos relatados em diferentes contextos educacionais (MANZKE, 2016). Assim, a formação continuada, que é prevista inclusive na legislação específica para a formação de professores (BRASIL, 2015), é um direito dos profissionais da educação. Os pedagogos podem beneficiar-se significativamente da formação continuada em música, em artes visuais, em dança e em teatro, a fim de estabelecerem bases para uma prática escolar que seja relevante para a formação dos estudantes, o que não isenta as instituições de ensino superior de incluírem na formação inicial do pedagogo estas áreas específicas.

\section{Polivalência ou interdisciplinaridade?}

A polivalência foi estabelecida com a inclusão da Educação Artística nos currículos escolares a partir de 1971, o que demandou a criação de cursos superiores de licenciatura em educação artística. Esta licenciatura tinha seu foco na formação integrada, como estabelecido pelo Parecer CFE $n^{\circ}$ 540/77 (BRASIL, 1977). Barbosa (2001, p. 48) analisa o ensino de arte no Brasil, afirmando que "[a] chamada polivalência é, na verdade, uma versão reduzida e incorreta do princípio da interdisciplinaridade, ou artes relacionadas, muito popular nas escolas americanas [...]"' Tal afirmação vincula-se a uma série de discussões propostas pela autora, incluindo a constatação sobre a cópia passiva de modelos estrangeiros no Brasil, que se refletem, também, na experiência da arte no currículo. A polivalência como experiência aplicada às artes de forma integrada, segundo Barbosa (2001), é uma cópia ou uma versão de um modelo já praticado fora do Brasil, mas aqui realizada de forma "reduzida e incorreta".

Sobre interdisciplinaridade, Fazenda (2012) apresenta uma discussão que situa histórica e conceitualmente sua presença no Brasil, evidenciando a complexidade desta abordagem em diversos contextos acadêmicos. Para aquela autora, "[...] é impossível a construção de uma única, absoluta e geral teoria da interdisciplinaridade" (FAZENDA, 2012, p. 13). Jantsch e Bianchetti (2011, p. 172) concordam que a "[...] interdisciplinaridade não é um conceito unívoco", o que é reiterado por Paviani (2014, p. 14), que afirma que a interdisciplinaridade "aponta para múltiplos significados e, em consequência, para nenhum significado preciso aceito pela comunidade de professores e pesquisadores".

$\mathrm{Na}$ década de 1970, a interdisciplinaridade estava relacionada a um modismo:

Passou a ser palavra de ordem a ser empreendida na educação, aprioristicamente, sem atentar-se para os princípios, muito menos para as dificuldades de sua realização. Impensadamente tornou-se a semente e 
o produto das reformas educacionais empreendidas entre 1968 e 1971 (nos três graus de ensino). (FAZENDA, 2012, p. 24, grifo do autor).

Esse período destacado por Fazenda (2012) coincide com a aprovação da Lei $n^{\circ} 5.692 / 71$, que instituiu a Educação Artística e, consequentemente, a prática polivalente. $\mathrm{O}$ destaque da autora para as ações "impensadas" nas reformas educacionais daquele momento converge para o que Barbosa (2001) chamou de "versão reduzida e incorreta do princípio da interdisciplinaridade", quando discute a polivalência.

Com relação à metodologia interdisciplinar na década de 1970, são destacadas por Fazenda (2012, p. 25), ao se referir aos estudiosos da época,

[...] a importância de se constituir uma equipe interdisciplinar, [...] necessidade do estabelecimento de conceitos-chave para facilitar a comunicação entre os membros da equipe, [...] exigências em se delimitar o problema ou a questão a ser desenvolvida, de repartição de tarefas e de comunicação dos resultados.

Ao se considerar esses princípios para a interdisciplinaridade na década de 1970, evidencia-se o contraste entre a proposta polivalente e a ação interdisciplinar, integrada, prevista nos documentos já mencionados anteriormente. A Educação Artística tornou-se responsabilidade de um único profissional que deveria "integrar" todas as artes, a partir de uma formação aligeirada e simplificada na licenciatura curta, complementada pela licenciatura plena em uma das áreas artísticas, o que novamente converge com a afirmação de Barbosa (2001) sobre a polivalência como "versão reduzida e incorreta do princípio da interdisciplinaridade".

Na década de 1980, outras discussões realizadas pelos estudiosos da área conduziram a avanços conceituais em relação à interdisciplinaridade, que foram sintetizados por Fazenda (2012) e que trazem elementos fundamentais para a compreensão e a prática de ações interdisciplinares. Nesta síntese, entre os vários elementos apresentados, pode ser destacado que "a interdisciplinaridade se desenvolve a partir do desenvolvimento das próprias disciplinas" (FAZENDA, 2012, p. 29). Paviani (2014, p. 7), ao apresentar elementos da "experiência interdisciplinar", afirma que "a verdadeira interdisciplinaridade é uma defesa das disciplinas e não sua eliminação". O autor chama atenção para o fato da interdisciplinaridade poder "tornar-se um mal-entendido, especialmente quando é assumida como uma meta ou solução absoluta e autônoma, anulando totalmente a existência das disciplinas" (PAVIANI, 2014, p. 7). Estes elementos trazidos por Fazenda (2012) e Paviani (2014) tornam-se indicativos relevantes para o entendimento de parte das críticas à polivalência para as artes, na medida em que se espera de um único profissional o desenvolvimento de uma disciplina que contempla várias áreas artísticas, que possuem campos teóricos específicos e que não se agrupam automaticamente por pertencerem ao campo das artes em geral. Mesmo considerando que não há uma definição única para interdisciplinaridade, o agrupamento das artes não representaria necessariamente uma prática interdisciplinar, pois não estaria contribuindo para uma nova abordagem que visaria a "noção do todo", a integração, a superação da fragmentação curricular.

A polivalência, de um modo geral, promoveu a superficialização da experiência com artes na formação universitária e na escola, em razão do pouco tempo destinado a cada área artística na formação e também no currículo escolar. A interdisciplinaridade trazia como proposta uma nova perspectiva que enfrentasse a fragmentação curricular, e a polivalência poderia estar alinhada, de certa forma, a esta mesma perspectiva. No entanto, o esvaziamento das disciplinas e a "diluição dos conteúdos" de cada área artística foi o resultado da prática polivalente, e por esta razão foi tão criticada e suprimida dos textos legais na década de 1990. Tal supressão nas orientações curriculares não significa que sua prática foi também suprimida ou extinta. Ao contrário, nos dias de hoje ainda se encontram diversos contextos educacionais que aplicam o ensino das artes de forma polivalente e há vários educadores que aplicam tais práticas porque são obrigados a isto, ou porque acreditam neste modelo tão amplamente criticado. Seriam necessárias mais pesquisas que estudassem sistematicamente os diferentes modelos de ensino das artes nas escolas, o que incluiria o estudo sistemático de práticas polivalentes. As evidências trazidas pelas pesquisas poderiam subsidiar novas discussões e decisões curriculares para o ensino das artes na escola. 
A prática da interdisciplinaridade na educação envolve, obrigatoriamente, professores. Fazenda (2012, p. 31) apresenta resultados de pesquisas que realizou no final da década de 1980 e no início dos anos 1990, que trazem características do professor interdisciplinar, como aquele que "[...] traz em si um gosto especial por conhecer e pesquisar, possui um grau de comprometimento diferenciado para com seus alunos, ousa novas técnicas e procedimentos de ensino, porém, antes, analisa-os e dosa-os convenientemente". Estas características seriam também possíveis de serem encontradas em professores que não sejam interdisciplinares necessariamente, o que reforça a noção de complexidade no exercício de definição e prática desta experiência educacional e a dificuldade de se estabelecer um conceito único ou amplamente aceito para a interdisciplinaridade: "Não existem fórmulas nem modelos" (PAVIANI, 2014, p. 19).

Em síntese, a interdisciplinaridade depende de vários fatores e condições que envolvem parceria, diálogo, troca, atitude e preparação de uma equipe disciplinar. "O conhecimento interdisciplinar busca a totalidade do conhecimento, respeitando-se a especificidade das disciplinas" (FAZENDA, 2012, p. 87). Parte destes elementos poderia estar relacionada à polivalência para as artes, mas os resultados desta prática surtiram efeitos insuficientes para uma proposta que visava à integração. Tal fragilidade nos resultados estaria diretamente relacionada com a quantidade e a qualidade da formação de professores nesta perspectiva, conduzindo, como consequência, a práticas escolares insuficientes para o desenvolvimento de experiências significativas com as artes.

\section{Algumas considerações}

A polivalência contribuiu - e ainda contribui - para a pouca valorização das artes no currículo, devido à superficialização de conteúdos e à falta de clareza sobre a relevância das artes na formação escolar. Toda esta discussão conduziu à definição de processos formativos em licenciaturas específicas para cada uma das linguagens artísticas, eliminando, assim, a perspectiva polivalente da formação de professores a partir de 2004. No entanto, esta discussão não atingiu de forma objetiva muitos sistemas educacionais que ainda contratam professores polivalentes e desejam estes profissionais em nome de uma concepção de ensino de artes, ou de uma tradição, ou ainda em função das razões econômicas e burocráticas relacionadas à presença de professores especialistas em cada uma das artes nas escolas.

No entanto, a defesa da especificidade de cada linguagem com relação ao ensino das artes não elimina ou extingue possibilidades de trabalhos interdisciplinares. Assim, desvincula-se os conceitos e as práticas da polivalência dos conceitos e das práticas interdisciplinares. A interdisciplinaridade não substitui a polivalência, quando se consideram os conceitos apresentados anteriormente com relação à 'defesa das disciplinas', pois a polivalência, de certa forma, promoveu uma junção das disciplinas artísticas sem a devida fundamentação disciplinar. Evidentemente tais afirmações não se aplicariam genericamente, já que existem sistemas educacionais que tratam das áreas artísticas de forma não polivalente (FIGUEIREDO; MEURER, 2016). O que se quer demarcar neste ponto do texto é que polivalência e interdisciplinaridade não são sinônimos, ou nomenclaturas diferentes para abordagens iguais. Há distinções claras na origem de tais conceitos e práticas.

Assim, a formação inicial do professor especialista, em curso de licenciatura específico em cada uma das linguagens artísticas, suprime a noção da polivalência no processo formativo, sendo possível a inclusão de experiências interdisciplinares em tal processo, desenvolvidas a partir de projetos que envolvessem parcerias entre professores de diferentes áreas do conhecimento. Neste processo formativo não se pretenderia que um único professor de uma disciplina fosse, individualmente, responsável pela integração com outras disciplinas.

$\mathrm{Na}$ formação inicial do pedagogo, no curso de pedagogia, as áreas de artes poderiam ser tratadas por especialistas em cada área artística, reiterando a formação específica do professor universitário. Desta forma, seria suprimida a noção de polivalência para as artes no processo formativo do pedagogo. O que a literatura tem relatado é, em muitos casos, a presença de um único professor no curso de Pedagogia responsável pela formação nas artes, como um todo. Novamente, experiências 
interdisciplinares seriam desejadas em tal processo formativo, já que o pedagogo atuará com todas as áreas do conhecimento escolar nos primeiros anos da escola, mas sem o enfraquecimento ou a anulação das disciplinas que comporiam tais experiências, o que se aplicaria também às disciplinas relacionadas a cada área artística.

O trabalho colaborativo entre pedagogos e especialistas em cada linguagem artística na escola é recomendado na literatura da área (WERLE; BELLOCHIO, 2009). Pedagogos e especialistas das artes desempenham diferentes papéis no processo de formação dos estudantes, e o trabalho conjunto pode favorecer inclusive esta definição das atribuições de cada profissional na escola. $\mathrm{O}$ pedagogo atua com as crianças regularmente, todos os dias, com todas as áreas do conhecimento escolar; o especialista atua de forma regular, mas espaçada, em horários específicos com cada turma.

Generalistas e especialistas desempenham papéis diferentes na escola, e antes de dizer que professores generalistas não possuem as condições adequadas para incluírem música na sua prática escolar, é preciso definir o que cada tipo de profissional deve fazer na escola.

[...] A presença do especialista em música poderia contribuir para o aprofundamento de atividades musicais, mas o professor generalista é aquele que está com as crianças a maior parte do tempo e poderia aproveitar muitas situações para incluir música no cotidiano escolar. (FIGUEIREDO, 2007, p. 34).

Experiências interdisciplinares seriam possíveis e desejadas na perspectiva de trabalhos colaborativos que envolvem, obrigatoriamente, parcerias entre profissionais da escola. Cada um destes profissionais tem seu papel e sua contribuição neste processo e assumir esta perspectiva poderia, de fato, conduzir a resultados satisfatórios com relação à atuação do pedagogo e o ensino das artes.

\section{Orientações legais para a formação de pedagogos}

A Resolução CNE/CP no 1/2006, que institui Diretrizes Curriculares Nacionais para o Curso de Graduação em Pedagogia, licenciatura, define
[...] princípios, condições de ensino e de aprendizagem, procedimentos a serem observados em seu planejamento e avaliação, pelos órgãos dos sistemas de ensino e pelas instituições de educação superior do país, nos termos explicitados nos Pareceres CNE/CP nos. 5/2005 e 3/2006. (BRASIL, 2006, p. 1).

Recortes específicos desse documento serão trazidos para o texto com o propósito de identificar aspectos referentes às artes e interdisciplinaridade. Tais recortes consideram de forma preponderante as orientações que incluem a formação inicial do professor que atua na Educação Infantil e nos anos iniciais do Ensino Fundamental.

$\mathrm{O}$ artigo 3 da referida resolução traz a interdisciplinaridade como um dos fundamentos a serem considerados:

O estudante de Pedagogia trabalhará com um repertório de informações e habilidades composto por pluralidade de conhecimentos teóricos e práticos, cuja consolidação será proporcionada no exercício da profissão, fundamentando-se em princípios de interdisciplinaridade, contextualização, democratização, pertinência e relevância social, ética e sensibilidade afetiva e estética. (BRASIL, 2006, p. 1).

Como apresentado anteriormente neste texto, não há uma visão única nem modelos e fórmulas específicas para a interdisciplinaridade. Desta forma, a indicação dos fundamentos da interdisciplinaridade, entre outros, na Resolução $\mathrm{CNE} / \mathrm{CP}$ $n^{\circ} 1 / 2006$, carece de orientações específicas sobre o que se entende por interdisciplinaridade e quais seriam estes fundamentos. Por um lado, é pertinente esta abertura, considerando a diversidade cultural brasileira e a autonomia dos sistemas educacionais; mas, por outro lado, a falta de clareza pode transformar tal prática "num modismo intelectual, ou, ainda, numa inútil justaposição de atividades" (PAVIANI, 2014, p. 9). A presença da interdisciplinaridade como fundamento no documento, portanto, poderia conduzir a distintos entendimentos e procedimentos.

O artigo $4^{\circ}$, item VI, a Resolução $n^{\circ} 01 / 2006$ define diversas atividades docentes, entre elas as áreas do conhecimento que deverão fazer parte de suas ações: "ensinar Língua Portuguesa, Matemática, Ciências, História, Geografia, Artes, Educação Física, de forma interdisciplinar e 
adequada às diferentes fases do desenvolvimento humano" (BRASIL, 2006, p. 2). As artes deverão estar incluídas obrigatoriamente na formação do pedagogo, uma vez que seu ensino está previsto como uma de suas atividades docentes. Ressalta-se que as artes são apresentadas no plural, sem maiores detalhamentos, e fazem parte das áreas que devem ser abordadas "de forma interdisciplinar", como previsto para todas as áreas. Verifica-se que não há uma definição clara sobre o ensino de artes, além do que a interdisciplinaridade poderia ser lida como polivalência para as artes, considerando os elementos já trazidos anteriormente neste texto. Evidentemente, uma diretriz nacional não traz todos os detalhamentos das ações definidas, mas há que se considerar que no ano de 2006 ainda vigorava certa indefinição sobre quais artes deveriam compor este componente curricular. A Lei $\mathrm{n}^{\circ}$ 11.769/08 estabeleceu a obrigatoriedade da música na educação básica (BRASIL, 2008) e em 2016 a LDB foi modificada pela Lei no 13.278/16, distinguindo as Artes Visuais, a Dança, a Música e o Teatro como áreas do componente curricular Arte (BRASIL, 2016). Dessa forma, trazendo esta atualização da LDB e considerando as orientações das diretrizes específicas, o pedagogo deveria ser capaz de atuar com estas quatro áreas das artes, o que implica na necessidade de formação nessas quatro áreas no seu curso superior. As pesquisas já mencionadas anteriormente indicam que esta não é necessariamente a realidade em diversos cursos de formação inicial. Assim, este item do artigo $4^{\circ}$ permite diferentes interpretações e práticas tanto do ponto de vista das Artes quanto da interdisciplinaridade.

$\mathrm{O}$ item XI do artigo $4^{\circ}$ da Resolução $\mathrm{CNE} / \mathrm{CP}^{\circ}$ $1 / 2006$ traz elementos que poderiam se relacionar à perspectiva interdisciplinar: "[...] desenvolver trabalho em equipe, estabelecendo diálogo entre a área educacional e as demais áreas do conhecimento" (BRASIL, 2006, p. 2). O texto indica uma prática de trabalho em equipe que pode pertencer ao conjunto de princípios da experiência interdisciplinar. No entanto, o que se verifica é que o que se espera do profissional formado no curso de pedagogia com relação ao trabalho em equipe na escola não é necessariamente exercitado durante o processo formativo na universidade, que é organizado em disciplinas e atividades que pouco dialogam, de um modo geral. As atividades interdisciplinares precisam de planejamento, "[...] pois raramente obtêm resultados positivos quando conduzidas de modo impensado" (PAVIANI, 2014, p. 63). O trabalho em equipe, portanto, dependerá de planejamento, de ações coletivas, da definição de tarefas e funções, que são práticas não tão presentes em cursos superiores. Dessa forma, o documento aponta para um caminho a ser seguido e que deveria ser mais focalizado e esclarecido na formação inicial do pedagogo e dos profissionais da educação, em geral, se a experiência interdisciplinar é desejada como um dos fundamentos no processo formativo na universidade.

O artigo $6^{\circ}$ da Resolução CNE/CP n ${ }^{\circ} 1 / 2006$ trata da estrutura do curso de Pedagogia, ressaltando a "diversidade nacional e a autonomia pedagógica das instituições" (BRASIL, 2006, p. 3). A autonomia institucional garante $\mathrm{o}$ atendimento a demandas específicas e contextuais, mas deve seguir a base que está estabelecida em diversos itens. O "núcleo de estudos básicos" deve articular vários aspectos da formação, incluindo:

[...] decodificação e utilização de códigos de diferentes linguagens utilizadas por crianças, além do trabalho didático com conteúdos, pertinentes aos primeiros anos de escolarização, relativos à Língua Portuguesa, Matemática, Ciências, História e Geografia, Artes, Educação Física. (BRASIL, 2006, p. 3).

As Artes são incluídas nos "estudos básicos”, mas, novamente, não há detalhamentos sobre tal inclusão. Na medida em que são definidas a "decodificação e utilização de códigos de diferentes linguagens" é preciso clareza sobre as linguagens artísticas, que possuem matrizes epistemológicas distintas, com códigos também distintos, e que necessitam de formação específica. A autonomia das instituições pode conduzir a vários entendimentos sobre como as artes seriam tratadas nesta perspectiva formativa do pedagogo. Como tratado anteriormente, há universidades que assumiram este compromisso de formação específica para cada linguagem artística, mas esta não tem sido a prática comum em diversas instituições do país. A presença de um professor de artes, polivalente, nos cursos de pedagogia ainda é notória em diversos cursos. 
Um “núcleo de estudos integradores" deverá ser parte da estrutura do curso de Pedagogia, de acordo com Artigo $6^{\circ}$ do mesmo documento. Estudos integradores podem fomentar práticas interdisciplinares, mas o documento não traz esta indicação de forma explícita. Estre as atividades propostas para "enriquecimento curricular" estão:

a) seminários e estudos curriculares, em projetos de iniciação científica, monitoria e extensão, e atividades práticas, de modo a propiciar vivências, nas mais diferentes áreas do campo educacional, assegurando aprofundamentos e diversificação de estudos, experiências e utilização de recursos pedagógicos; [...] (BRASIL, 2006, p. 3).

A indicação de estudos integradores poderá contribuir no processo de formação do pedagogo, mas as orientações do documento analisado são genéricas, podendo resultar em ações muito ou pouco significativas, dependendo das ações institucionais, já que há limites de vagas para bolsistas de iniciação científica ou de extensão ou de monitoria, por exemplo, o que conduziria ao atendimento reduzido de estudantes que poderiam beneficiar-se de tal formação; atividades práticas e vivências são indicações também genericamente apresentadas e não definem claramente o que pode ser incluído nesta perspectiva que poderia ampliar a formação para a prática interdisciplinar ou não, dependendo de ações específicas dos cursos formadores.

Esse recorte de pontos específicos da Resolução $\mathrm{CNE} / \mathrm{CP}^{\circ}{ }^{\circ}$ 1/2006 (BRASIL, 2006) traz elementos que indicam imprecisão ou falta de clareza para que funcionem, de fato, como diretrizes para os cursos de Pedagogia no que tange à formação em Artes e interdisciplinaridade. A ausência do termo polivalência pode significar algum direcionamento em termos de procedimentos pedagógicos das artes para a formação do licenciado em Pedagogia, mas o texto das diretrizes pode ser interpretado de várias maneiras, inclusive considerando a polivalência como a prática desejada para a formação no curso de Pedagogia em nome da integração das áreas. A interdisciplinaridade está presente em diversos pontos do texto, o que poderia conduzir ao entendimento de polivalência no caso das artes, considerando a integração proposta e reiterada ao longo do documento. Em ambos os casos, não se explicita a abordagem relacionada à preparação do pedagogo com relação às artes, nem se indica quais seriam os princípios fundamentais relacionados à interdisciplinaridade.

Além dessa Resolução específica para o curso de Pedagogia, em 2015 foi aprovada a Resolução $\mathrm{CNE} / \mathrm{CP}^{\circ}$ 2, de 01 de julho de 2015, que "Define as Diretrizes Curriculares Nacionais para a formação inicial em nível superior (cursos de licenciatura, cursos de formação pedagógica para graduados e cursos de segunda licenciatura) e para a formação continuada" (BRASIL, 2015). Estes dois documentos se complementam, sendo o primeiro voltado especificamente para a formação do licenciado em Pedagogia, e o segundo dirigido para todos os cursos de licenciatura do país. Algumas considerações sobre a Resolução $\mathrm{CNE} / \mathrm{CP}$ n $^{\circ}$ 2/2015 são apresentadas a seguir.

As diretrizes de 2015 trazem diversos elementos que reiteram pontos anteriormente tratados nas diretrizes de 2006 para os cursos de Pedagogia, além de acrescentarem outros aspectos referentes à formação inicial e continuada para cursos de licenciatura, cursos de formação pedagógica para graduados e cursos de segunda licenciatura. Sendo um documento genérico, não são tratados aspectos referentes às especificidades da formação de todas as licenciaturas, portanto, não há referências explícitas à formação em artes, não havendo correlação explícita ou direta entre esse texto e a perspectiva polivalente para as artes.

Com relação à interdisciplinaridade, o termo é recorrente nesse documento de 2015 e aparece em diversos pontos da resolução. A seguir, uma seleção de trechos que incluem a interdisciplinaridade no texto:

[...] CONSIDERANDO os princípios que norteiam a base comum nacional para a formação inicial e continuada, tais como: a) sólida formação teórica e interdisciplinar; b) unidade teoria-prática; c) trabalho coletivo e interdisciplinar [...] (BRASIL, 2015, p. 2, grifo nosso).

[...] CONSIDERANDO a docência como ação educativa e como processo pedagógico intencional e metódico, envolvendo conhecimentos específicos, interdisciplinares e pedagógicos, conceitos, princípios e objetivos da formação [...] (BRASIL, 2015, p. 2, grifo nosso). 
[...] As Diretrizes Curriculares Nacionais para a Formação Inicial e Continuada em Nível Superior de Profissionais do Magistério para a Educação Básica aplicam-se à formação de professores [...] nas diferentes áreas do conhecimento e com integração entre elas, podendo abranger um campo específico e/ou interdisciplinar [...] (BRASIL, 2015, p. 3, grifo nosso).

[...] Para fins desta Resolução, a educação contextualizada se efetiva, de modo sistemático e sustentável, nas instituições educativas, por meio de processos pedagógicos entre os profissionais e estudantes articulados nas áreas de conhecimento específico e/ou interdisciplinar e pedagógico [...] (BRASIL, 2015, p. 4, grifo nosso).

[...] O projeto de formação deve ser elaborado e desenvolvido por meio da articulação entre a instituição de educação superior e o sistema de educação básica, [...] e deve contemplar: I - sólida formação teórica e interdisciplinar dos profissionais [...] (BRASIL, 2015, p. 5, grifo nosso).

[...] A formação de profissionais do magistério deve assegurar a base comum nacional, [...] para que se possa conduzir o(a) egresso(a): I - à integração e interdisciplinaridade curricular, dando significado e relevância aos conhecimentos e vivência da realidade social e cultural, consoantes às exigências da educação básica e da educação superior para o exercício da cidadania e qualificação para o trabalho [...] (BRASIL, 2015, p. 6, grifo nosso).

[...] IV - dominar os conteúdos específicos e pedagógicos e as abordagens teórico-metodológicas do seu ensino, de forma interdisciplinar e adequada às diferentes fases do desenvolvimento humano [...] (BRASIL, 2015, p. 8, grifo nosso).

O que se verifica nessa resolução com relação à interdisciplinaridade é praticamente o mesmo que foi analisado com relação à Resolução CNE/ CP no 1/2006 (BRASIL, 2006) referente ao curso de Pedagogia. O termo é utilizado com frequência, sugerindo certa centralidade deste procedimento interdisciplinar, tanto para a formação quanto para a atuação do egresso. O texto não esclarece de que forma esta experiência interdisciplinar deveria ser estabelecida nos cursos de licenciatura, ficando a cargo das instituições formadoras a organização curricular, a definição de bases teóricas e a aplicação prática de conhecimentos relacionados ao ensino e à aprendizagem em uma abordagem interdisciplinar.

Outros trechos do documento destacam o "desenvolvimento de ações que valorizem o trabalho coletivo, interdisciplinar e com intencionalidade pedagógica clara para o ensino e o processo de ensino-aprendizagem" (BRASIL, 2015, p. 7), além do "conhecimento multidimensional e interdisciplinar sobre o ser humano e práticas educativas" (BRASIL, 2015, p. 10). Ou seja, a interdisciplinaridade é parte integrante indiscutivelmente das definições da Resolução CNE/CP n ${ }^{\circ}$ 2/2015, aplicável a todas as licenciaturas, sem que se assuma uma base teórica e conceitual que possa auxiliar e esclarecer procedimentos, experiências e programas interdisciplinares. As instituições formadoras definirão estes aspectos, o que poderia comprometer, em certa medida, a concretização de um projeto de "consolidação das normas nacionais para a formação de profissionais do magistério para a educação básica", considerada "indispensável para o projeto nacional da educação brasileira" (BRASIL, 2015, p. 1). O mesmo comprometimento poderia ser pensado considerando que essas diretrizes apresentam "os princípios que norteiam a base comum nacional para a formação inicial e continuada [...]" (BRASIL, 2015, p. 2). Neste sentido poderia ser questionado o que se entende por base nacional comum, já que a autonomia das instituições formadoras associada à falta de bases teóricas na orientação legal para a estruturação de cursos de licenciatura poderia conduzir a processos muito distintos, produzindo resultados também distintos com relação a uma base nacional. Interdisciplinaridade, neste caso, seria uma opção? O documento sugere que não é uma opção, mas a ausência de referenciais mais precisos sobre o que seria interdisciplinaridade neste contexto formativo, e como deveria ser aplicada curricularmente na formação dos professores, poderia conduzir a resultados que não avançam no sentido de qualificar os profissionais da educação. Parafraseando Paviani (2014), a interdisciplinaridade poderia trazer elementos de flexibilização e integração das diversas disciplinas de um currículo, mas também poderia ser mal-entendida, conduzindo a resultados indesejados, que podem fragilizar a formação ao invés de fortalecê-la. 


\section{Considerações finais}

As Diretrizes Curriculares Nacionais para o Curso de Graduação, licenciatura (BRASIL, 2006) e as Diretrizes Curriculares Nacionais para a formação inicial em nível superior (cursos de licenciatura, cursos de formação pedagógica para graduados e cursos de segunda licenciatura) e para a formação continuada (BRASIL, 2015) foram analisadas a partir de dois focos específicos: o ensino das artes e a interdisciplinaridade. A seleção de trechos específicos para análise dos dois documentos apresenta aspectos positivos, trazendo orientações que visam ao aprimoramento da educação brasileira como um todo a partir da formação de profissionais que atuarão na Educação Básica. Ao mesmo tempo, tais documentos carecem de maior consistência no que diz respeito à fundamentação dos processos formadores de novos profissionais para a educação. No caso do curso de Pedagogia, é positiva a presença das Artes como componente curricular, mas falta clareza na forma de organização e aplicação de disciplinas que cumpririam este componente curricular. A questão da polivalência não é tratada de forma explícita, mas poderia, na prática, ser mantida em razão de vários fatores, dentre eles a tradição de ensino de artes nestes cursos, a presença de profissionais polivalentes ministrando disciplinas de artes, a compreensão da função das artes na formação do professor e, consequentemente, dos alunos, dentre outros.

Com relação à interdisciplinaridade, o termo aparece de forma recorrente nos dois documentos analisados, mantendo a mesma perspectiva ampla, aberta, sem definições esclarecedoras sobre os conceitos que embasariam tal procedimento na formação de professores. A hegemonia dos modelos disciplinares não parece compatível com as propostas interdisciplinares, o que significa que há certa contradição entre a lei e a prática da lei. A ênfase na disciplinaridade, historicamente, vem ocupando espaço predominante, o que significa que a adoção da interdisciplinaridade depende de mudanças sistemáticas e profundas nos processos de formação universitária, o que inclui a revisão de modelos e também a formação do quadro docente para a atuação na perspectiva interdisciplinar. Assim, o documento legal aponta para o que se deseja, mas não estabelece caminhos ou orientações mais consistentes para que se conquiste a condição de uma nova perspectiva educacional, de fato, que poderia, então, estar sendo refletida na prática dos professores nas escolas.

Essa breve análise de pontos específicos dos documentos, em diálogo com a literatura específica que diz respeito à formação do pedagogo, evidencia a necessidade de mais estudos e pesquisas que possam auxiliar na compreensão de processos que são complexos por natureza, como a interdisciplinaridade (FAZENDA, 2012), por exemplo, associada às áreas artísticas em cursos de Pedagogia. Formar professores interdisciplinares não é tarefa que se cumpre a partir de textos legais de forma automática; depende de ações pontuais que poderiam estar melhor dimensionadas em documentos oficiais.

Os resultados positivos de pesquisas já realizadas com relação às artes na formação do pedagogo evidenciam possibilidades que deveriam estar mais claramente disseminadas no meio acadêmico. Além disso, estes resultados deveriam conduzir a ações mais efetivas no sentido de se compreender para que servem as artes na formação do pedagogo e qual o seu papel na formação escolar. Não é mais necessário afirmar que os pedagogos têm pouca formação musical ou artística, ou que se sentem inseguros com os conteúdos das artes em sua prática, ou que as artes são compreendidas como entretenimento no processo escolar, e assim por diante. Isto já está claramente anunciado e denunciado pelas pesquisas realizadas. Bellochio (2000, p. 125) afirmava não haver, "na maioria das vezes, um diálogo, aberto, crítico e conjunto sobre alguns encaminhamentos, mais sólidos, que poderiam ser realizados entre os dois cursos". Passadas quase duas décadas desta afirmação de Bellochio (2000), ainda se encontra pouco diálogo entre cursos. É necessário avançar propositivamente para que as licenciaturas nas diversas linguagens artísticas e os cursos de Pedagogia assumam um diálogo que conduza à efetivação de práticas que sejam pertinentes em termos de formação e de atuação dos professores da Educação Infantil e dos anos iniciais do Ensino Fundamental.

A polivalência, apesar de não estar mais presente textualmente nos documentos norteadores da formação de professores, ainda é encontrada nos 
cursos de Pedagogia, mantendo uma perspectiva amplamente debatida e criticada por seus resultados insatisfatórios. Caberia uma provocação, talvez, àqueles que consideram a polivalência um modelo adequado para o ensino das artes, no sentido de produzirem trabalhos que demonstrassem e fundamentassem este modelo. $\mathrm{O}$ mesmo seria indicado para administradores escolares que, em diversos casos, produzem orientações e normatizações sem a devida consistência ou justificativa teórica, ignorando as mudanças na legislação com relação à formação de professores de artes e a produção acadêmica sobre o ensino das artes.

A interpretação dos textos legais, com suas ambiguidades e imprecisões, tem contribuído para a manutenção de práticas pouco eficientes até os dias de hoje, como é o caso do ensino das artes em vários contextos. Mudanças são desejadas não apenas para o cumprimento da lei, mas para o estabelecimento de novas perspectivas que possam inserir as artes de forma significativa na formação escolar, participando de um projeto de formação integral de fato, dialogando com as demandas da sociedade contemporânea, o que implica, portanto, que a formação dos pedagogos deve também ser fortalecida no que diz respeito às artes e seu ensino.

Seria fundamental a realização de pesquisas que estudassem sistematicamente os diferentes modelos de ensino das artes praticados em universidades e escolas, o que incluiria o estudo sistemático de práticas polivalentes e interdisciplinares, identificando e fundamentando tais práticas em contextos reais. As evidências trazidas por novas pesquisas, somadas às contribuições dos trabalhos já realizados, poderiam subsidiar novas discussões e decisões curriculares para o ensino das artes na escola de forma mais consistente e realista. Estas pesquisas poderiam tratar da formação e da atuação dos especialistas nas diversas áreas artísticas e dos pedagogos em diferentes contextos, incluindo a análise das mudanças que vêm sendo promovidas a partir das orientações legais que definem e subsidiam a criação, a atualização e a manutenção de cursos de licenciatura.

Os documentos oficiais são revistos, ampliados, revogados, substituídos, em um processo dinâmico, marcado por diversas ações ou omissões dos diversos segmentos envolvidos com os processos educacionais escolares. Cabe aos profissionais da educação, especialistas ou pedagogos, administradores, além da sociedade, zelar pela qualidade da educação oferecida no país. Os professores de música, das artes visuais, da dança e do teatro não poderão resolver todos os desafios sozinhos, mas, sem dúvida, deverão assumir compromissos em seus diversos campos de atuação para que a música e as demais artes estejam presentes nos processos de formação na educação básica e na educação superior de forma consistente. Grandes desafios já foram enfrentados pelos profissionais do ensino das artes, evidenciando a possibilidade de se conquistar novos e mais dignos espaços para as artes na escola. Profissionais cada vez mais preparados para continuar enfrentando os desafios que se apresentam hoje e que certamente serão também apresentados no futuro é uma das metas para a melhoria da educação brasileira. E os profissionais que lidam com as artes na escola, sejam pedagogos ou professores especialistas, certamente fazem parte deste coletivo que trabalha em busca da formação de seres humanos mais completos.

\section{REFERÊNCIAS}

BARBOSA, Ana Mae. John Dewey e o ensino de arte no Brasil. 3. ed. São Paulo: Cortez, 2001.

BELLOCHIO, Cláudia Ribeiro. A educação musical nas séries iniciais do ensino fundamental: olhando e construindo junto as práticas cotidianas do professor. 2000. 423f. Tese (Doutorado em Educação) - Faculdade de Educação, Programa de Pós-Graduação em Educação, Universidade Federal do Rio Grande do Sul. Porto Alegre, 2000.

BRASIL. Presidência da República. Lei no 5.692, de 11 de agosto de 1971. Fixa Diretrizes e Bases para o ensino de $1^{\circ}$ e $2^{\circ}$ graus, e dá outras providências. Brasília, DF, 1971. Disponível em: <http://www2.camara.leg.br/legin/ fed/lei/1970-1979/lei-5692-11-agosto-1971-357752-publicacaooriginal-1-pl.html>. Acesso em: 10 jan. 2017.

Parecer CFE $n^{\circ} 540$, de 10 de fevereiro de 1977. Sobre o tratamento a ser dado aos componentes curri$\overline{\text { culares }}$ previstos no art. $7^{\circ}$ da Lei 5.692/71. Documenta, Rio de Janeiro, n. 195, p. 22-34, fev. 1977. Disponível 
em: <http://www.histedbr.fe.unicamp.br/navegando/ fontes_escritas/7_Gov_Militar/parecer n. 540-1977 sobre o tratamento a ser dado aos comp curriculares.pdf $>$. Acesso em: 10 jan. 2017.

Lei de Diretrizes e Bases da Educação Nacional (LDB): Lei 9.394/96. Brasília, DF: Diário Oficial da União, Ano CXXXIV, n. 248, de 23/12/96, p. 27.833-27.841, 1996.

Parâmetros Curriculares Nacionais $\left(1^{\mathrm{a}}\right.$ a $\left.4^{\mathrm{a}}\right)$. Brasília, DF: Ministério da Educação/ Secretaria de Educação Fundamental, 1997.

. Ministério da Educação. Resolução CNE/CES n 2, de 8 de março de 2004. Aprova as Diretrizes Curriculares Nacionais do Curso de Graduação em Música e dá outras providências. Brasília, DF, 2004a. Disponível em: <http://portal.mec.gov.br/cne/arquivos/pdf/CES02-04.pdf >. Acesso em: 05 jan. 2017.

. Ministério da Educação. Resolução CNE/CES no 3, de 8 de março de 2004. Aprova as Diretrizes Curriculares Nacionais do Curso de Graduação em Dança e dá outras providências. Brasília, DF, 2004b. Disponível em: $<$ http://portal.mec.gov.br/cne/arquivos/pdf/CES03-04.pdf>. Acesso em: 05 jan. 2017.

Ministério da Educação. Resolução CNE/CES no 4, de 8 de março de 2004. Aprova as Diretrizes Curriculares Nacionais do Curso de Graduação em Teatro e dá outras providências. Brasília, DF, 2004c. Disponível em: $<$ http://portal.mec.gov.br/cne/arquivos/pdf/CES04-04.pdf>. Acesso em: 05 jan. 2017.

. Ministério da Educação. Resolução CNE/CP n 1, de 15 de maio de 2006. Institui Diretrizes Curriculares Nacionais para o Curso de Graduação em Pedagogia, licenciatura. Brasília, DF, 2006. Disponível em: <http://portal. mec.gov.br/cne/arquivos/pdf/rcp01_06.pdf $>$. Acesso em: 03 jan. 2017.

. Presidência da República. Lei no 11.769, de 18 de agosto de 2008. Altera a Lei n. 9.394/96, para dispor sobre a obrigatoriedade do ensino de música na educação básica. Brasília, DF, 2008. Disponível em: <http://www. planalto.gov.br/ccivil_03/_ato2007-2010/2008/lei/111769.htm>. Acesso em: 02 jan. 2017.

Ministério da Educação. Resolução CNE/CES no 1, de 16 de janeiro de 2009. Aprova as Diretrizes Curriculares Nacionais do Curso de Graduação em Artes Visuais e dá outras providências. Brasília, DF, 2009. Disponível em: <http://portal.mec.gov.br/cne/arquivos/pdf/2009/rces001_09.pdf>. Acesso em: 05 jan. 2017.

. Ministério da Educação. Resolução CNE/CP no 2, resolução no 2 de $1^{\circ}$ de julho de 2015. Define as Diretrizes Curriculares Nacionais para a formação inicial em nível superior (cursos de licenciatura, cursos de formação pedagógica para graduados e cursos de segunda licenciatura) e para a formação continuada. Brasília, DF, 2015. Disponível em: $<$ http://portal.mec.gov.br/index.php?option=com_docman\&view=download\&alias=17719-res-cnecp-002-03072015\&category_slug=julho-2015-pdf\&Itemid=30192>. Acesso em: 10 jan. 2017.

Presidência da República. Lei no 13.278, de 2 de maio de 2016. Altera o § 60 do art. 26 da lei no 9.394, de 20 de dezembro de 1996, que fixa as diretrizes e bases da educação nacional, referente ao ensino da arte. Brasília, DF, 2016. Disponível em <http://presrepublica.jusbrasil.com.br/legislacao/3333393820/lei-13278-16>. Acesso em: 20 ago. 2016.

DALLABRIDA, Iara Cadore; SOUZA, Zelmieden Adornes de; BELLOCHIO, Cláudia Ribeiro. "Deu um tempinho, vamos fazer uma musiquinha!": a música nos anos iniciais do ensino fundamental. In: BELLOCHIO, Cláudia Ribeiro; GARBOSA, Luciane Wilke Freitas (Org.). Educação musical e pedagogia: pesquisas, escutas e ações. Campinas, SP: Mercado de Letras, 2014. p. 143-168.

DEL-BEN, Luciana. Et al. Sobre a docência de música na educação básica: uma análise de editais de concurso público para professor. Opus, v. 22, n. 2, p. 543-567, dez. 2016.

FAZENDA, Ivani Catarina Arantes. Interdisciplinaridade: história, teoria e pesquisa. 18. ed. Campinas, SP: Papirus, 2012.

FIGUEIREDO, Sergio Luiz Ferreira de. The music preparation of generalist teachers in Brazil. 2003. 364f. Tese (Doutorado em Filosofia) - Faculdade de Educação, Royal Melbourne Institute of Technology (RMIT) University, Melbourne, Austrália, 2003.

Teaching music in the preparation of generalist teachers: A Brazilian experience. Bulletin of the Council for Research in Music Education, n. 161/162, p. 73-81, 2004a.

A preparação musical de professores generalistas no Brasil. Revista da ABEM, Porto Alegre, v. 11, p. $\overline{55-62,2004 b .}$

A pesquisa sobre a prática musical de professores generalistas no Brasil: situação atual e perspectivas para o futuro. Em Pauta, v. 18, n. 31, p. 30-50, 2007. 
. O ensino de música na educação brasileira: um breve panorama a partir da legislação educacional. In: ALCÂNTARA, Luz Marina; TEXEIRA, Edvânia Braz (Org.). O ensino de música: desafios e possibilidades contemporâneas, v. 1. Goiânia: SEDUC/Governo de Goiás, 2009. p. 81-89.

FIGUEIREDO, Sergio Luiz Ferreira de; MEURER, Rafael Prim. Educação musical no currículo escolar: uma análise dos impactos da Lei no 11.769/08. Opus, v. 22, n. 2, p. 515-542, dez. 2016.

FLICK, Uwe. Introdução à pesquisa qualitativa. Tradução Joice Elias Costa. 3. ed. Porto Alegre: Artmed, 2009.

FONTERRADA, Marisa Trench de Oliveira. De tramas e fios: um ensaio sobre música e educação. São Paulo: Editora da UNESP, 2005.

FUCKS, Rosa. O discurso do silêncio. Rio de Janeiro: Enelivros, 1991.

GIL, Antonio Carlos. Como elaborar projetos de pesquisa. 4. ed. São Paulo: Atlas, 2002.

HENTSCHKE, Liane; OLIVEIRA, Alda. Music curriculum development and evaluation based on Swanwick's theory. International Journal of Music Education, v. 34, p. 14-29, 1999.

JANTSCH, Ari Paulo; BIANCHETTI, Lucídio. Universidade e interdisciplinaridade. In: ciplinaridade: para além da filosofia do sujeito. 9. ed. Petrópolis, RJ: Vozes, 2011. p. $\overline{172-182}$.

(Org.). Interdis-

MANZKE, Vitor Hugo Rodrigues. Formação musical de professores generalistas: uma reflexão sobre o processo de formação continuada. 2016. 157f. Dissertação (Mestrado em Música) - Centro de Artes, Programa de Pós-Graduação em Música, Universidade do Estado de Santa Catarina, Florianópolis, 2016. Disponível em: <http:// sistemabu.udesc.br/pergamumweb/vinculos/00001e/00001edd.pdf×. Acesso em: 03 jan. 2017.

OESTERREICH, Frankiele; GARBOSA, Luciane Wilke Freitas. A história da disciplina música no curso de pedagogia da UFSM (1984-2008) In: BELLOCHIO, Cláudia Ribeiro; GARBOSA, Luciane Wilke Freitas (Org.). Educação musical e pedagogia: pesquisas, escutas e ações. Campinas, SP: Mercado de Letras, 2014. p. 89-116.

PAVIANI, Jayme. Interdisciplinaridade: conceitos e distinções. 3. ed. Caxias do Sul, RS: Educs, 2014.

PENNA, Maura. Professores de música nas escolas públicas de ensino fundamental e médio: uma ausência significativa. Revista da ABEM, nº 7, p. 7-19, 2002.

Música(s) e seu ensino. 2. ed. Porto Alegre: Sulina, 2010.

PEREIRA, Joana Lopes. Et al. Modos de conceber a docência de música na educação básica: uma análise de editais de concursos públicos para professores. In: CONGRESSO DA ASSOCIAÇÃO NACIONAL DE PESQUISA E PÓS-GRADUAÇÃO EM MÚSICA, 24., 2014, São Paulo. Anais... São Paulo: ANPPOM, 2014.

SCHEIBE, Leda; DURLI, Zenilde. Curso de Pedagogia no Brasil: olhando o passado, compreendendo o presente. Educação em Foco, v. 14, n. 17, p. 79-109, jul. 2011.

STORI, Regina. As Diretrizes Curriculares de Arte do Estado do Paraná: uma análise dos fundamentos e da gestão do ensino de música em Ponta Grossa/PR (2003-2010). 2011. 192f. Dissertação (Mestrado em Educação) - Universidade Estadual de Ponta Grossa, Ponta Grossa, PR, 2011.

SUBTIL, Maria José Dozza. A Lei n. 5.692/71 e a obrigatoriedade da educação artística nas escolas: passados quarenta anos, prestando contas ao presente. Revista Brasileira de História da Educação, Campinas-SP, v. 12, n. 3, p. 125-151, set./dez. 2012.

TOURINHO, Irene. Usos e funções da música na escola pública de $1^{\circ}$ grau. Fundamentos da Educação Musical, ABEM, Porto Alegre, v. 1, 91-113, 1993.

UNIVERSIDADE DO ESTADO DE SANTA CATARINA - UDESC. Projeto Político Pedagógico do Curso de Licenciatura em Pedagogia. Florianópolis: FAED, 2010. Disponível em: <http://www.faed.udesc.br/arquivos/ id_submenu/495/pedagogia_2012.pdf $>$. Acesso em: 08 jan. 2017.

WERLE, Kelly; BELLOCHIO, Cláudia Ribeiro. A produção científica focalizada na relação professores não-especialistas em música e educação musical: um mapeamento de produções da Abem. Revista da ABEM, Porto Alegre, v. 22, p. 29-39, set. 2009. 